\title{
A TRANSMISSION PROBLEM FOR THE HELMHOLTZ EQUATION WITH HIGHER ORDER BOUNDARY CONDITIONS
}

\author{
A. M. SIMÕES
}

Abstract. The present paper deals with some properties for certain classes of Wiener-Hopf operators associated with a wave diffraction problem. This diffraction problem is mathematically modeled by the Helmholtz equation and higher order boundary conditions on an infinite strip. Different types of operator relations are exhibited for different kinds of operators acting between Lebesgue and Bessel potential spaces on a finite interval and on the positive half-line. In particular, the operators under study are analyzed in detail in what concerns their Fredholm property. At the end, an operator normalization procedure is applied to the critical orders of the spaces where the problem is not normally solvable.

Mathematics subject classification (2010): 35J05, 35J25, 47B35, 35S05, 47A53, 45E10, 47F05, 35R25. Keywords and phrases: Boundary value problem, Helmholtz equation, Bessel potential space, convolution type operator, Fredholm operator, higher order boundary condition, Wiener-Hopf operator, not normally solvable operators, image normalization.

\section{REFERENCES}

[1] H. BaRT AND V. E. TSEKANOVSKII, Matricial coupling and equivalence after extension, Oper. Theory Adv. Appl. 59 (1992), 143-160.

[2] A. Böttcher, Yu. I. Karlovich And I. M. Spitkovsky, Convolution Operators and Factorization of Almost Periodic Matrix Functions, Birkhäuser Verlag, Basel, 2002.

[3] A. BÜYÜKAKSOY AND G. ÇÝNAR, Solution of a matrix Wiener-Hopf equation connected with the plane wave diffraction by an impedance loaded parallel plate waveguide, Math. Methods Appl. Sci. 28 (2005), 1633-1645.

[4] L. P. CAStro, Solution of a Sommerfeld diffraction problem with a real wave number, in: C. Constanda, M. Ahues, A. Largillier (eds.), Integral Methods in Science and Engineering, Birkhäuser, Boston, MA, 25-30, 2004.

[5] L. P. CASTRO, Strongly elliptic operators for a plane wave diffraction problem in Bessel potential spaces, JIPAM, J. Inequal. Pure Appl. Math.3, 2 (2002), Paper No. 25, 9 p., electronic only-Paper No. $25,9 \mathrm{p}$.

[6] L. P. CASTRO, Wiener-Hopf operators on unions of finite intervals: relations and generalized inversion, in: F. J. Cobos (ed.) et al., Proceedings of the Meeting on Matrix Analysis and Applications, University of Sevilha, Sevilha, 148-155, 1997.

[7] L. P. CAStro, R. Duduchava And F.-O. SPECK, Localization and minimal normalization of some basic mixed boundary value problems, Factorization, Singular Operators and Related Problems, Proceedings of the Conference in Honour of Professor Georgii Litvinchuk, (2002), Funchal, Kluwer Academic Publisher, 73-100, 2003.

[8] L. P. CASTRO And D. KaPAnAdZE, Dirichlet-Neumann-impedance boundary-value problems arising in rectangular wedge diffraction problems, Proc. Am. Math. Soc. 136 (2008), 2113-2123.

[9] L. P. CASTRO AND D. KAPANADZE, The impedance boundary-value problem of diffraction by a strip, Journal of Mathematical Analysis and Applications 337, 2 (2008), 1031-1040.

[10] L. P. CASTRO AND D. KAPANADZE, Wave diffraction by a half-plane with an obstacle perpendicular to the boundary, J. Differential Equations 254 (2013), 493-510. 
[11] L. P. Castro And A. Moura Santos, An Operator Approach for an Oblique Derivative Boundary-Transmission Problem, Mathematical Methods in the Applied Sciences 27, 12 (2004), 1469-1491.

[12] L. P. CASTRO AND D. NATROShVILI, The potential method for the reactance wave diffraction problem in a scale of spaces, Georgian Math. J. 13 (2006), 251-260.

[13] L. P. CASTRO AND A. M. SIMÕES, Fredholm analysis for a wave diffraction problem with higher order boundary conditions on a strip, in: Mathematical Problems in Engineering and Aerospace Sciences, Cambridge Scientific Publishers, Cambridge, 535-542, 2009.

[14] L. P. Castro And A. M. Simões, Fredholm Analysis for a Wave Diffraction Problem with Higher Order Boundary Conditions on a Union of Strips, Application of Mathematics in Technical and Natural Sciences, American Institute of Physics, 1186, 49-56, 2009.

[15] L. P. CASTRO AND A. M. SimõeS, Integral equation methods in problems of wave diffraction by a strip with higher order reactance conditions, American Institute of Physics, AIP - Conf. Proc., 1493, 904-910, 2012.

[16] L. P. CASTRO AND A. M. SimÕES, Mathematical treatment of a wave diffraction problem with higher order boundary conditions, in: Trends and Challenges in Applied Mathematics, Matrix Rom Publishers, Bucharest, 44-49, 2007.

[17] L. P. CAStro And A. M. Simões, On the Solvability of a Problem of Wave Diffraction by a Union of a Strip and a Half-Plane, Application of Mathematics in Technical and Natural Sciences: Proceedings of the 2nd International Conference, American Institute of Physics, 1301, 85-96, 2010.

[18] L. P. CAstro And A. M. Simões, The Impedance problem of Wave Diffraction by a Strip with Higher Order Boundary Conditions, American Institute of Physics, AIP - Conf. Proc., 1561, 184193, 2013.

[19] L. P. CASTRO AND F.-O. SPECK, Relations between convolution type operators on intervals and on the half-line, Integral Equations Operator Theory 37 (2000), 169-207.

[20] L. P. CAstro, F.-O. Speck And F. S. TeiXeIra, Explicit solution of a Dirichlet-Neumann wedge diffraction problem with a strip, J. Integral Equations Appl. 5 (2003), 359-383.

[21] L. P. Castro, F.-O. Speck And F. S. Teixeira, On a class of wedge diffraction problems posted by Erhard Meister, Oper. Theory Adv. Appl. 147 (2004), 213-240.

[22] D. Colton And R. KRESS, Inverse Acoustic and Electromagnetic Scattering Theory, SpringerVerlag, Berlin, 1998.

[23] V. Galdi AND I. M. Pinto, Derivation of higher-order impedance boundary conditions for stratified coatings composed of inhomogeneous-dielectric and homogeneous-bianisotropic layers, Radio Science 35, 2 (2000), 287-303.

[24] T. W. Hungerford, Algebra, Springer Verlag, New York, 1974.

[25] D. S. Jones, Methods in Electromagnetic Wave Propagation. Volume 1: Theory and Guided Waves. Volume 2: Radiating Waves, Clarendon Press, Oxford, 1987.

[26] A. B. KUIJPER, A note on first kind convolution equations on a finite interval, Integral Equations Operator Theory 14 (1991), 146-152.

[27] A. B. KuiJPER AND I. M. SPITKOVSKIJ, On convolution equations with semi-almost periodic symbols on a finite interval, Integral Equations Operator Theory 16 (1993), 530-538.

[28] E. MEISTER, Some multiple-part Wiener-Hopf problems in mathematical physics, in: Mathematical Models and Methods in Mechanics, Banach Center Publ., vol. 15, PWN, Polish Scientific Publishers, Warsaw, 359-407, 1985.

[29] E. MeISTER AND F.-O. SPECK, Modern Wiener-Hopf methods in diffraction theory, in: Ordinary and Partial Differential Equations, vol. II, Pitman Res. Notes Math. Ser., vol. 216, Longman Sci. Tech., Harlow, 130-171, 1989.

[30] A. Moura Santos, Minimal Normalization of Wiener-Hopf Operators and Applications to Sommerfeld Diffraction Problems, Disertao para obtensao do grau de Doutor em Matemática, Instituto Superior Técnico, 113 pg., 1999.

[31] A. Moura Santos And N. J. Bernardino, Image Normalization of Wiener-Hopf Operators and Boundary-Transmission Value Problems for a Junction of two Half-Planes, Journal of Mathematical Analysis and Applications 377 (2011), 274-285.

[32] A. Moura Santos, F.-O. Speck and F. S. Teixeira, Compatibility conditions in some diffraction problems, in: Direct and Inverse Electromagnetic Scattering, Pitman Res. Notes Math. Ser., Longman, Harlow, 361, 25-38, 1996. 
[33] A. Moura Santos, F.-O. Speck and F. S. Teixeira, Minimal Normalization of Wiener-Hopf Operators in Spaces of Bessel Potentials, Journal of Mathematical Analysis and Applications 225 (1998), 501-531.

[34] P. A. SAntos AND F. S. TEIXEIRA, Sommerfeld half-plane problems with higher order boundary conditions, Math. Nachr. 171 (1995), 269-282.

[35] T. B. A. SENIOR, Approximate boundary conditions, IEEE Trans. Antennas Propag., AP-29, 5 (1981), 826-829.

[36] T. B. A. SENIOR AND J. L. Volakis, Derivation and application of a class of generalized boundary conditions, IEEE Trans. Antennas Propag., AP-37, 12 (1989), 1566-1572.

[37] A. H. SERBEST, A review on the diffraction on high-frequency electromagnetic waves by half-planes and plane discontinuities, in: M. Hashimoto, M. Idemen and O. A. Tretyakov (eds.), Analytical and Numerical Methods in Electromagnetic Wave Theory, Science House Company, Tokyo, 1992.

[38] A. Sommerfeld, Mathematische Theorie der Diffraction, Math. Ann. 47 (1896), 317-374.

[39] F.-O. SPECK, On the reduction of linear systems related to boundary value problems, in: The Vladimir Rabinovich Anniversary Volume (Eds: Yu. Karlovich et al.), Operator Theory: Advances and Applications, 228, Birkhäuser, Basel, 391-406, 2013.

[40] J. L. Volakis AND T. B. A. SENIOR, Application of a class of generalized boundary conditions to scattering by a metal-backed dielectric half-plane, Proc. IEEE 77, 5 (1989), 796-805. 